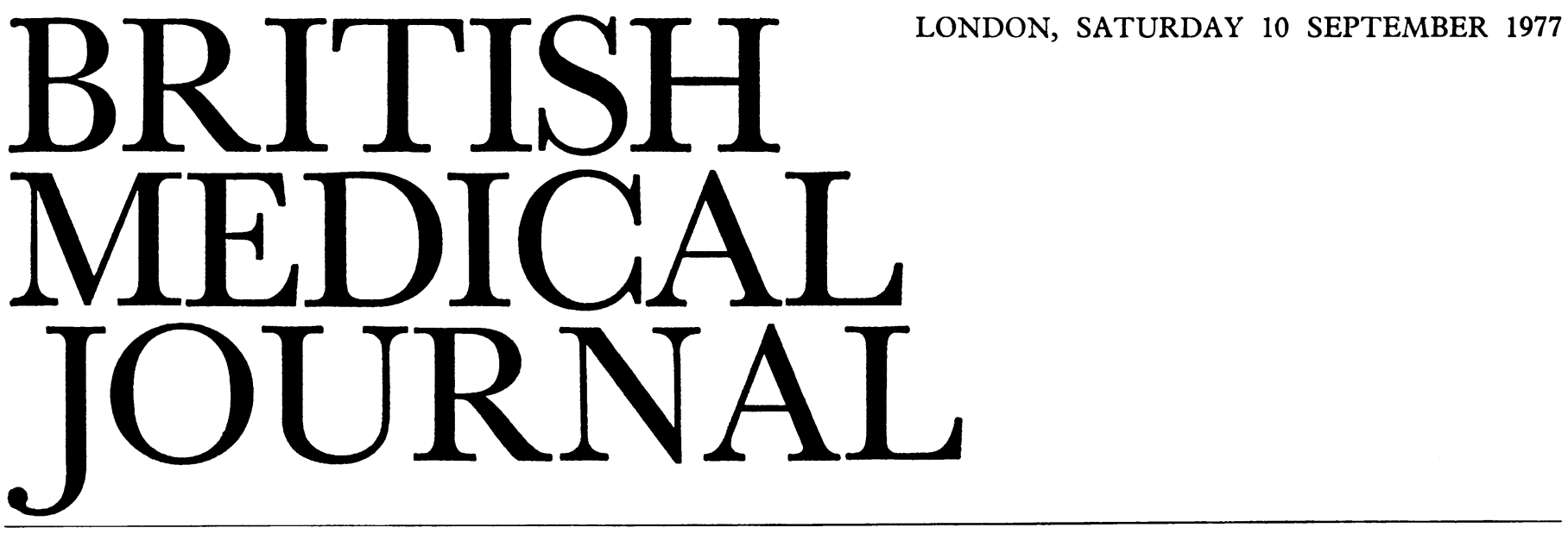

The distinction between angina and myocardial infarction stole into the consciousness of the medical profession between 1915 and 1930, at different rates in different countries. ${ }^{1-5}$ The pathology of infarction was described, ${ }^{2}$ and emphasis was later placed on dating the infarct from its histological appearance and on the process of healing as the collagen fibres develop. ${ }^{6}$ These appear in about 12 days, become prominent in three weeks, and reach their maximum in about two months, after which there is little further change and healing may be regarded as complete.

Rest for damaged structures being an axiom of medicine, it was natural that prolonged physical immobility should have been prescribed for myocardial infarction. This regimen held rigid sway for about a quarter of a century, reinforced by dire warnings about the danger of aneurysm formation ${ }^{8}$ in patients mobilised too soon. Thus, six weeks' bed rest was about the norm. ${ }^{9}$ Then in 1952 Levine and Lown ${ }^{10}$ boldly intrcduced their "armchair treatment" for acute coronary thrombosis in words that can still profitably be read: "The abruptness of the onset of coronary thrombosis, with its grave prognostic connotations, afflicting as it frequently does the highly active and frequently healthy person, when coupled with long continued bed rest, saps morale, provokes desperation, unleashes anxiety and ushers in hopelessness with respect to resumption of normal living." Since then a series of papers ${ }^{11-18}$ has followed this cue, the cautious, almost apologetic theme being to reduce the period of immobility for thousands of sufferers with acute infarction and shorten their stay in hospital. The latest article, ${ }^{19}$ from Edinburgh, is confident in advocating rapid mobilisation. Patients with uncomplicated infarctions were up after two days' bed rest, and with a programme of rehabilitation $46 \%$ of the 105 eligible for re-employment were back at work in three months and $86 \%$ in six months. The authors declare that no further evidence for the safety of early mobilisation is needed.

We can now accept that early mobilisation of the patient with an uncomplicated infarct will not increase morbidity or mortality. In particular, there need be no fear of inducing myocardial rupture in the early days ${ }^{14}$; indeed, most ruptures occur at rest or in sleep. ${ }^{20}$ Similarly, there is solid evidence that early mobilisation does not increase the later incidence of aneurysm..$^{11} 1319$ The still wary physician may gain courage from the results of caring for patients at home ${ }^{21}$ and by remembering that perhaps half of all infarcts go unrecognised, ${ }^{22}{ }^{23}$ often with no bed rest at all.
A recent report by the Royal College of Physicians and the British Cardiac Society on cardiac rehabilitation ${ }^{24}$ gives much useful information and advice but avoids dogmatic recommendations. A questionnaire to British cardiologists in $1970^{25}$ showed that, while $75 \%$ of cardiologists thought that special rehabilitation services for cardiac patients were desirable, only 23 out of 113 said that such services existed in their areas. It is doubtful whether there has been much change since. The central issue is the importance of a formal programme of physical training in a physiotherapy department or gymnasium. Such a programme can undoubtedly improve the physique and morale ${ }^{26}$ of many patients and increase work performance and cardiac output. Against this must be set the expense and time, the high drop-out rate, and the uncertainty that the long-term prognosis is improved. ${ }^{24}$ Much depends on the enthusiasm of the individual clinician, and some doubt whether such a formal programme is truly and universally helpful, or whether it reflects what physicianly benevolence feels ought to be helpful.

The hospital physician today is best advised to have no rigid rules about mobilisation but to suit his management to the patient as he adapts his clothing to the weather. $\mathrm{He}$ is fully justified in getting a patient with an uncomplicated infarct out of bed in a day or two and discharging him within 10 days-or even a week when there is help at home. But patients with complications will require a different regimen. With all patients the doctor should take an optimistic attitude from the start, assume a return to normal life, and see the patient not more than a month ${ }^{27}$ after he leaves hospital. By this time the infarct will have healed, the patient can report on further symptoms and exercise capacity, cardiac function can be assessed objectively, and the patient and his general practitioner can be advised on further activity and return to work.

Of all common conditions the prognosis of coronary disease is one of the least predictable. Too timid management is often worse than too robust, so we may all feel relieved that the well-intentioned but unjustified restrictions of the past are over.

\footnotetext{
${ }^{1}$ Herrick, J B, Fournal of the American Medical Association, 1912, 59, 2015

2 Levine, S A, and Brown, C L, Medicine, 1929, 8, 245.

${ }^{3}$ McNee, J W, Quarterly fournal of Medicine, 1925, 19, 44.

4 Gibson, A G, Lancet, 1925, 2, 1270.

${ }_{5}^{5}$ Parkinson, J, and Bedford, D E, Lancet, 1928, 1, 4.

${ }^{6}$ Mallory, G K, et al, American Heart fournal, 1939, 18, 648.

${ }^{7}$ Lodge-Patch, I, British Heart fournal, 1951, 13, 37.
} 
8 Schlichter, J, et al, Medicine, 1954, 33, 43.

9 Duke, D, American Heart fournal, 1971, 82, 486.

10 Levine, S A, and Lown, B, fournal of the American Medical Association, 1952, 148, 1365.

11 Groden, B M, et al, Scottish Medical fournal, 1967, 12, 435.

12 Adgey, A A J, British Heart fournal, 1969, 31, 750.

13 Harpur, J E, et al, Lancet, 1971, 2, 1331.

14 Royston, G R, British Heart fournal, 1972, 34, 526.

16 Tucker, H H, et al, British Medical fournal, 1973, 1, 10.

16 Medical Division, Royal Infirmary, Glasgow, Lancet, 1973, 2, 346.

17 Hayes, M J, et al, British Medical fournal, 1974, 3, 10.

18 Abraham, A S, et al, New England fournal of Medicine, 1975, 292, 719.

19 Thornley, P E, and Turner, R W D, British Heart Fournal, 1977, 39, 471.

${ }^{20}$ Mitchell, J R A, and Parish, D J, British Medical fournal, 1960, 2, 1626.

${ }^{21}$ Mather, H G, et al, British Medical fournal, 1976, 1, 925.

22 Medalie, J H, and Goldbourt, U, Annals of Internal Medicine, 1976, 84, 526.

${ }^{23}$ Lancet, 1976, 2, 449.

24 Joint Working Party, Royal College of Physicians of London and British Cardiac Society, Fournal of the Royal College of Physicians, 1976, 9, 281. 25 Groden, B M, et al, British Heart fournal, 1971, 33, 756.

${ }^{26}$ Carson, P, et al, British Medical fournal, 1973, 4, 213.

27 Kushnir, B, et al, Scandinavian fournal of Rehabilitation Medicine, 1975, 7, 158.

\section{Day services for mentally handicapped adults}

Many of the mildly handicapped committed to hospital in the past as feeble-minded were in fact capable of remunerative work and could have been integrated into the general community. ${ }^{1}$ Indeed, classification was imprecise, and many of this group were within the normal range of intelligence. ${ }^{2}$ In addition, the more severely handicapped (formerly termed imbeciles) are nowadays known to be capable of useful work in a sheltered setting, given suitable training and facilities. ${ }^{3}$ For much of this century a major shortcoming on the part of those providing for the mentally handicapped has been the underestimation of their potential for social adaptation. ${ }^{4}$

As attitudes and expectations have changed demands have grown for community care and "normalisation." As Penrose ${ }^{5}$ put it, "Civilised communities must learn to tolerate, to absorb, and to employ the scholastically retarded and to pay more attention to their welfare." Community care is a fine slogan, but all too often the sole alternative to admission of the more severely handicapped to an institution has been a perpetual domestic burden for parents, with all the selfsacrifice that this entails. There were few occupation centres before the second world war and almost none when it ended, but more recently there has been a dramatic increase in the number of places available. (Since the 1970 Education Act came into effect in 1971 severely mentally handicapped children have been included within the educational system as of right, so that training centres, as the former occupation centres are now called, relate strictly to adults.)

In a preface to what is modestly described as a pamphlet ${ }^{6}$ by the National Development Group for the Mentally Handicapped-in reality an excellent miniature textbook and guidethe Secretary of State for Social Services gives a figure of 24500 for 1969 with a target of 73000 over 20 years and a 1976 achievement of 34000 places in adult training centres. Gratifying though this rise may be, it does not help those many families with a handicapped member at home all day with no suitable occupation or training. The problem is most severe with the most severely handicapped: only $13 \%$ of training centres have a special care unit, ${ }^{7}$ while others are inclined to refuse individuals with multiple handicap or profound retardation. These are the very cases whose families have the greatest need for daily relief from their care.

The National Development Group suggests that in future adult training centres be known as social education centres, a welcome shift of emphasis towards continued education and training as opposed to mere occupation. Much, however, depends on resources. The DHSS has repeatedly stated that current economies must not affect the plans for the mentally handicapped, so long neglected. But if there are overall cuts in budgets of local authorities and health authorities it is difficult to believe the programme will not suffer. Again, ideally the mildly handicapped should find work in the community, but with rising unemployment they compete instead with the severely handicapped for places in training centres. The National Development Group rightly says that labels such as "over-protecting" or "rejecting" should be avoided in describing families of the handicapped, but unless urgently needed places in centres are provided both terms may well apply. The designation "occupation centre" may be outmoded, but nevertheless occupation is of cardinal importance. The pamphlet devotes a brief chapter to preparation for work, but in reality it is only the mildly handicapped who can hope for open employment, and this after much effort. A rational economy would provide adequate employment for the mentally handicapped of all grades in industry and ordinary work-places as well as in specialised centres.

${ }^{1}$ O'Connor, N, and Tizard, J, The Social Problem of Mental Deficiency. London, Pergamon Press, 1956.

${ }^{2}$ Kirman, B H, and Bicknell, J, Mental Handicap. Edinburgh, Churchill Livingstone, 1975.

${ }^{3}$ Mental Deficiency-the Changing Outlook, ed A M Clarke and A D B Clarke, 3rd edn. London, Methuen, 1974.

4 Clarke, A D B, and Hermelin, B F, Lancet, 1955, 2, 337.

5 Penrose, L S, The Biology of Mental Defect, 4th edn. London, Sidgwick and Jackson, 1972.

${ }^{6}$ National Development Group for the Mentally Handicapped, Day Services for Mentally Handicapped Adults. London, HMSO, 1977.

Whelan, E, and Speake, B, Adult Training Centres in England and Wales: Report of the First National Survey. Manchester, University of Manchester, Hester Adrian Research Centre, 1977.

\section{Control of salmonellosis in poultry and cattle}

Salmonellosis in animals causes serious economic loss to farmers and food producers, and it is also the source of many human infections. Thus the decision to make vets responsible for implementing the Zoonoses Order of 1975 seems sensible. Nevertheless, the medical and veterinary approaches to the control of salmonellosis differ considerably. ${ }^{1}$

Of the 23609 cases of salmonellosis occurring in animals during $1968-74,86 \%$ occurred in cattle, $7 \%$ in poultry, $3 \%$ in sheep, and $2 \%$ in pigs; furthermore, the incidence in poultry seems to be decreasing. Yet most human salmonellosis in the United Kingdom is attributed to poultry and pork. ${ }^{2-4}$ These figures suggest a conflict of interest between the veterinarians, who will be concerned mainly with cattle, and the medical profession, whose efforts at control will be aimed more at poultry and pigs.

Salmonellas cause symptoms in cattle more often than in pigs or poultry, so cattle infections are clearly more likely to be investigated. But both fowls and pigs can excrete salmonella serotypes that have been introduced in animal feed without 